\title{
A propriedade privada dos bens de produção e a regulação
}

\author{
Private ownership of productive assets and regulation
}

\author{
Wander Henrique de Almeida Costa ${ }^{1}$ \\ Giovani Clark ${ }^{2}$
}

\begin{abstract}
Resumo
Este artigo apresenta um perfil das origens da propriedade privada dos bens de produção e o tratamento dado pelo Estado a ela através dos tempos. A concretização da propriedade privada trouxe novas formas de convivências e transformações para a história da humanidade. No Direito, especialmente no Direito Econômico, como a política econômica tratou juridicamente aquela. Apresentamos também um retrato histórico das origens e da evolução do comércio e da indústria até a formação dos cartéis, quando as grandes corporações privadas buscam, através de ajuste de preços, o incremento de seu poder político e econômico. Contudo veremos que no paradigma do Estado Democrático de Direito este regula a economia de mercado, passando a ser mais controlador que ator, ou seja, ao substituir o Estado Social, pelo novo modelo constitucional de participação estatal, substituiu-se também o Neoliberalismo de regulamentação pelo Neoliberalismo de regulação. No novo paradigma, a pratica de abuso do poder econômico é combatida via limitação da autonomia privada e ações positivas, acentuando-se o papel das agências de regulação em prol da proteção dos mercados, da defesa dos consumidores e de uma sociedade democrática.
\end{abstract}

Palavras Chave: Poder econômico privado; Propriedade privada dos bens de produção; Cartéis; Agências de regulação; Neoliberalismo de regulamentação e regulação.

\begin{abstract}
This article is an outline of the origins of private ownership of productive assets and the treatment given to it by the State through the ages. The implementation of private property has brought new forms of conviviality and transformations in the history of mankind. In law, especially in Economics Law, such as economic policy that dealt with legally.We also present a historical picture of the origins and evolution of trade and industry until the formation of cartels, when large private corporations seeking, through adjustment of prices, increase their political and
\end{abstract}

\footnotetext{
${ }^{1}$ Pesquisador da Fundação Brasileira de Direito Econômico, Mestrando em Direito Público pela PUC/MG Contato: whac1956@ hotmail.com

${ }^{2}$ Doutor em Direito Econômico pela UFM G, Presidente da Fundação Brasileiro de Direito Econômico, Docente em Direito Econômico na UFM G e PUC/M G - Contato: gclark@pucminas.br
} 
economic power. However we see that the paradigm of a democratic state that regulates the market economy, becoming more controlling than actor, or to replace the welfare state, the new constitutional model of state involvement, was also replaced the neoliberalism of the regularization by the neoliberalism of the regulation. In the new paradigm, the practice of abuse of economic power is countered via limitation of autonomy and positive actions, emphasizing the role of regulation agencies to promote the protection of markets, consumer protection and a democratic society.

Keywords: Private economic power; Private ownership of productive assets; Cartels; Regulation agencies, Neoliberalism; Regularization and regulation.

\section{Introdução}

0 artigo traz uma reflexão sobre a evolução da propriedade privada dos bens de produção durante a história, bem dos tipos de Estado. Versa ainda do abuso do poder econômico realizado pelo referido tipo de propriedade, via os cartéis, que na atualidade operam no seio social com mais força (não raramente) do que o Estado e a sociedade civil organizada.

Pretende-se demonstrar que a partir das mutações da sociedade, o Estado desenvolveu e reinventou-se diversas vezes para amparar a propriedade privada dos bens de produção, como ocorreu com a transformação do Estado Social em Estado Democrático de Direito, acompanhada pela virada do neoliberalismo de regulamentação para 0 de regulação. Nessa nova ordem o Estado minimizou o seu papel de empresário para ser regulador.

No novo paradigma, a prática de abuso do poder econômico é combatida via limitação da autonomia privada e sanções legais, acentuando-se, supostamente, o papel do Estado enquanto regulador e protetor dos mercados, dos consumidores e da democracia.

0 trabalho utiliza as contribuições do antropologista norte-americano Lewis Henry Morgan, a partir da obra de Engels, que traçou um perfil das origens da família, da propriedade privada e do Estado. Neste tópico verifica-se o surgimento da propriedade privado, findando a coletiva, e a criação do Estado para dar suporte a uma sociedade individualista e patrimonialista privada.

Em uma sucessão de fatos, verifica-se a desconstrução do modelo econômico Mercantilista implantado no Estado Absolutista. A teoria M ercantilista consistia na idéia que 
a riqueza de uma nação expressava-se pela acumulação de metais preciosos, bem como no crescimento das exportações e limitação das importações.

O Estado de Direito construído no apagar das luzes do Estado Absolutista, trouxe consigo uma nova mentalidade no âmbito econômico. A burguesia no controle político do Estado tratou de afastá-lo teoricamente da economia, mas na prática ele se manteve realizado políticas econômicas e sociais favoráveis a aquelas.

Ao tratar do neoliberalismo de regulamentação e de regulação, o trabalho expõe a transformação do Estado Social, criado para minimizar as agruras das classes desfavorecidas, para o Estado Democrático de Direito, alterando-se também a forma de intervenção estatal, agora regulador. Contudo, o neoliberalismo de regulação resultou no aumento da concentração econômica e de práticas de abuso do poder econômico como os cartéis.

\section{Propriedade privada - origens e socialização}

Para Engels (2007) a formação da sociedade moderna com base na propriedade privada só foi possível após o desmoronamento do modelo familiar primitivo uma vez que a economia doméstica era calcada na subsistência, onde não havia produção de excedentes tornando o comércio e o acúmulo de riquezas desnecessário.

A família primitiva era reconhecida como gens que designava de forma geral um agrupamento de consangüíneos, por linhagem de uma descendência comum, posteriormente foi ocorrendo à miscigenação de gens e a família passou a ser conhecida como comunista. Isso porque viviam em grupos fechados onde não havia necessidade de produção de excedentes (alimentos e bens), já que o produzido bastava para eles. Tanto as terras como os filhos eram comuns.

Esta realidade foi se modificando através dos séculos, quando ocorreram transformações que desembocaram na sociedade moderna, com uma agricultura e produção de bens em grande escala, na descoberta de novos territórios, nas guerras e no intenso comércio internacional.

Ao trazer as contribuições de Lewis Henry Morgan (1818-1881), antropologista norte-americano, Engels (2007) revela no livro “A origem da família, da propriedade privada e do Estado" que a humanidade passou por três estágios: Selvagem, Barbárie e Civilização. 
No Estágio Selvagem, em sua fase inferior, pode-se dizer na infância do gênero humano, os homens viviam praticamente em árvores, tinham como característica uma "linguagem" restrita e se alimentavam de raízes, frutos e nozes.

Posteriormente, na fase média deste primeiro estágio, com a descoberta do fogo, incluiu-se na dieta dos homens os peixes, crustáceos e outros animais aquáticos possibilitando uma maior liberdade de movimentação, já que podiam percorrer longas distâncias margeando os rios, sem perder uma fonte segura de alimentação. Ressalta Morgan que a nova dieta trouxe a libertação e independência para a humanidade viabilizando-a a se espalhar pelo planeta terra.

$\mathrm{Na}$ fase superior do Estágio Selvagem, ocorre à invenção do arco e da flecha, outros animais, abatidos através da caça, passam a integrar o cardápio regular dos homens. Nessa fase outros saberes são adquiridos, inclusive para a construção de moradias com utilização de madeira e plantas e a convecção de utensílios de madeira ou de junco trançados.

Com a descoberta da cerâmica se faz um giro no primeiro estágio e inicia-se o segundo, o da Barbárie, em sua fase inferior. Neste período, a partir da trança de junco, se amoldava barro para guardar água e alimentos, descobriu-se ainda que após a secadura do barro o jarro não necessitava mais do junco para se manter firme. Iniciava-se aí a domesticação de animais e o cultivo de plantas.

$\mathrm{Na}$ fase superior da Barbárie, o homem funde o ferro e, posteriormente, com a invenção da escrita passa para a fase da Civilização. Nesse estágio da civilização se registra o emprego do arado de ferro puxado por animais, o incremento da produção agrícola, a derrubada de matas, a maior fixação do homem em determinado local, acarretando um aumento da população e 0 adensamento da povoação em pequenas áreas.

As famílias primitivas foram à fronteira do homem com a propriedade privada, mas a cobiça, a avidez de prazeres e o roubo da propriedade comum romperam essa barreira, uma vez que a riqueza passou a ser valorizada, os saques e a violência passaram a ser meios de aquisição das riquezas coletivas. Uma vez adquiridas, digo, individualizadas a força, as propriedades precisavam ser protegidas, advindo daí a consagração da sua forma privada (incluído as de produção), em oposição às tradições comunistas gentílicas pré-históricas, em um tempo em que tudo era de todos. 
A história da humanidade pode ser contada como a história da conquista e desenvolvimento de uma minoria oprimindo causadora de sofrimentos a uma grande maioria.

$\mathrm{Na}$ aurora ateniense, 600 a.C., os meios de opressão utilizados pela minoria contra a maioria eram a usura e o dinheiro. Com o sistema monetário instituído, ele foi o catalisador da sociedade moderna e a derradeira destruição das famílias comunistas. 0 sistema monetário penetrou como um veneno no seio das antigas famílias primitivas que sobreviviam baseadas na economia natural. Os atenienses já haviam inventado também as letras de câmbio e as hipotecas as quais eram utilizadas como garantia nos contratos de empréstimos feitos aos pequenos agricultores.

As pequenas áreas dos agricultores eram assim hipotecadas e ao final do prazo de quitação dos empréstimos eram tomadas (dos inadimplentes) pelos "possuidores do dinheiro" que se davam por satisfeitos em permanecer na terra de seus algozes como colonos trabalhando por um sexto do produzido. Tendo, por vezes, que vender os seus próprios filhos como escravos ou perderem os mesmos por terem sido colocados como garantia adicional ao pagamento dos empréstimos.

Em Roma a gens se dissipou com os conflitos ocorridos entre a plebe e o populus romanus, formado exclusivamente pelas gens. Nesta época o rex Sérvio Túlio, baseado em modelos gregos criou uma Assembléia do Povo baseada nas posses de cada um e os cidadãos eram dispostos por ordem militar, formados por companhias de cem homens, cada uma das quais tinha um voto. Nessa "nova ordem constitucional" segue "toda a história da república romana, com suas lutas entre patrícios e plebeus pelo acesso aos cargos públicos, pela participação na distribuição das terras do Estado (Engels, 2007:143)“. Esta luta prossegue até a derrocada dos nobres patrícios com o surgimento de uma nova classe de proprietários rurais, possuidores de dinheiro e das terras.

$\mathrm{Na}$ dimensão de imensos latifúndios retirados pelos possuidores do dinheiro das mãos dos camponeses rurais ocorreu o despovoamento da Itália, de vez que os novos proprietários cultivavam suas terras com escravos. Despovoada a Itália abriram-se as portas não apenas para o "império como também para seus sucessores, os bárbaros germânicos.(Engels, 2007, p. 143)". 
A queda de Roma foi um marco na história da civilização, uma vez que as invasões bárbaras no ocidente fizeram com que as famílias, os camponeses e os pequenos agricultores se aglomerassem em burgos feudais para garantia de sobrevivência às hordas que vinham do norte. Dos burgos dos senhores feudais abriu-se caminho para os EstadosNacionais, tendo o Mercantilismo como sua principal política econômica do período até o desmoronamento do Absolutismo com a criação dos Estados Liberais de Direito dos pensadores oitocentistas franceses no Século das Luzes.

No giro constitucional do Estado liberal para o Estado social nasce para as propriedades privadas uma nova dimensão social de utilização da terra, ora denominada de função social da propriedade. 0 Estado Democrático de Direito na atualidade também segue a mesma linha e fixa a função social das propriedades, no caso brasileiro, seja dos bens individuais (art. 5, XXII da CR) e dos bens de produção (art. 170, III da CR).

Entendemos como propriedades dos bens de produção como todos os bens utilizados (terra, maquinas, fabricas, tecnologia, dinheiro) no processo produtivo a fim de satisfazer as necessidades humanas. Ou seja, os meios que propiciam a produção de bens e serviços aos homens. Ensina o Novo Dicionário de Direito Econômico em relação aos bens de produção: "Bens de produção - são bens voltados à elaboração de outros bens, à produção de riquezas (2010, p. 77)".

Ademais, segundo 0 § 2을 do artigo 182 da Constituição da República brasileira, "cumpre sua função social a propriedade urbana quando satisfaz as exigências fundamentais de ordenação da cidade expressas no plano diretor." São os ditames constitucionais para o exercício da propriedade produtiva urbana, a terra, à cargo do legislador ordinário.

No caso da propriedade rural pode ser desapropriada para realização da reforma agrária quando, conforme 0 artigo 186 da nossa Constituição, não cumpre os mandamentos constitucionais relativamente ao aproveitamento racional e adequado, bem como utilização correta dos recursos naturais disponíveis, entre outros requisitos, ou seja, não cumpre a função social da propriedade rural produtiva.

Explica Barreto (2005) que "a função social da propriedade é elemento essencial à propriedade" e que atualmente abstrai-se que "não há propriedade sem atendimento à função social.", para ratificar sua posição, traz as colaborações de Telga de Araújo (Enciclopédia Saraiva de Direito, v.39, p.7, 1977): 


\begin{abstract}
"Desde Santo Ambrósio, propugnando por uma sociedade mais justa com a propriedade comum, ou Santo Agostinho, condenando o abuso do homem em relação aos bens dados por Deus, e Santo Tomás de Aquino, que vê na propriedade um direito natural que deve ser exercido com vistas ao bonum commune, até aos sumos pontífices que afinal estabeleceram as diretrizes do pensamento católico sobre a propriedade, sempre em todas as oportunidades, a Igreja apreciou a questão objetivando humanizar o tratamento legislativo e político do problema".
\end{abstract}

Dessa maneira verificamos como a propriedade coletiva das famílias comunistas se transformou em propriedade privada, com víeis individualista e irrestrita, a partir do implemento da agricultura, indústria e do comércio, motivada pela avidez de riquezas, e posteriormente, a partir do Estado Social e até nos dias atuais do Estado Democrático de Direito, a propriedade dos bens de produção se agregou o conceito de função social, tornando-se elemento essencial à mesma.

Ademais, a Carta Política do Brasil de 1988, em seus arts. 173, parágrafo 4; e 174, dentre outros, impõe limites ao uso das propriedades dos bens de produção e ações positivas para as mesmas, bem como impõe a normatização daquelas a fim de efetivar os comandos constitucionais e implantar o nosso Estado Democrático de Direito.

\title{
A construção do modelo liberal e a queda do império mercantilista
}

No Estado Monárquico absolutista quando a figura do soberano se confundia com a do Estado não havia liberdade para o indivíduo e consequentemente não existiam leis que assegurasse seus direitos. Nesta época, dos Estados-Nacionais, a política econômica adotada no ocidente era denominada de Mercantilismo e consistia em uma série de ações estatais no processo produtivo, incluindo incentivos e limitações às propriedades destinadas a aquele fim, no intuito de fortalecer o mercado interno.

A teoria M ercantilista adotava a idéia de que a riqueza de uma nação consistia na acumulação de metais preciosos, ouro e prata, principalmente, obtidos através do aumento das exportações e restrição concomitante das importações e/ ou via colônias.

o Estado Mercantilista intervinha fortemente na economia incentivando novas indústrias, controlando o mercado interno e promovendo a colonização de novos territórios, como forma de aquisição de matérias-primas e garantia do escoamento de produtos manufaturados para um mercado cativo. 
Segundo Pereira (2010), o Estado Absolutista Monárquico e seu mercantilismo, fundamentais ao fortalecimento da burguesia e dos Estados nacionais, passaram a limitar a expansão dos mercados e dos lucros. Assim sendo, nada melhor do que uma desconstrução daquele tipo de Estado e construção do Estado de Direito.

Nesse contexto ressalta o citado autor sobre os filósofos liberais:

Dentro desse contexto de transformação do modo de produção feudal para 0 capitalismo, emerge uma série de autores que inovam nas idéias acerca do Estado, da Sociedade e da Economia. Esses autores promovem uma revolução na forma de pensar, comum ao homem no feudalismo. Tornam-se revolucionários no sentido de propor mudanças radicais tanto para o Estado como para a Sociedade e para a Economia. Os liberais, como passaram a ser conhecidos os integrantes deste grupo de pensadores agruparam-se, constituindo uma corrente do pensamento que prima pela liberdade, em seu sentido lato, para o homem feudal. Estes pensadores se puseram contra a ordem feudal, propondo um mundo novo, no qual a liberdade para produzir e comercializar as mercadorias, assume grande significado. A liberdade política e econômica emerge no cenário de discussão dos filósofos e políticos da época (Pereira, 2010)

Nota-se, portanto, por este prisma, que o pensamento liberal do Século das Luzes não tinha somente uma conotação política dissociada da prática econômica da época. A burguesia a quem interessava o "afastamento" do Estado do domínio econômico, digo, uma técnica renovada de atuação no âmbito socioeconômico, influenciou de forma aguda os fisiocratas franceses, principalmente, no sentido literal que hoje ressoa a palavra liberdade. Eles aclamavam o Laissez-Faire como quase uma Fé religiosa fundamentalista.

Laissez-faire tornou-se o lema dos fisiocratas franceses que viveram na época de Gournay. Eles são importantes porque constituem a primeira escola de economistas. Formavam um grupo que a partir de 1757, se reunia regularmente sob a presidência de François Quesnay para examinar problemas econômicos. Os membros da escola escreveram livros e artigos pedindo a eliminação das restrições, defendendo o comércio livre, o laissez-faire. (Huberman, 1978, p. 149)

Precisavam de liberdade para conduzir seus negócios e como tal, detentores do poder econômico, se puseram a trabalhar para modificar a intervenção estatal. Quando a monarquia e seu Estado absolutista foram substituídos pelo Estado de Direito e pelo liberalismo Liberal as aclamadas: liberdade, fraternidade e igualdade forma esquecidas pelas praticas políticas e pelas ações socioeconômicas estatais. 
Após obter o poder político a partir das revoluções oitocentistas e o controle da economia, a burguesia liberal mantém as políticas sociais pregadas pelas idéias liberais apenas como formalidade, ou seja, simbolismo inalcançável para as grandes massas populares, conforme acentua Maullaz (2010): [...] Uma vez detentora do controle político da sociedade, a burguesia não mais se interessa em manter como apanágio de todos os homens, a prática universal dos princípios filosóficos de sua revolta social.".

Paralelamente às mudanças políticas ocorriam também alterações nas formas de produção, de divisão do trabalho e do comércio interno e externo. Conforme Huberman (1978) a história da indústria mostra a evolução deste segmento com origem caseira que evolui até alcançar a chamada revolução industrial. Daí em diante, aquela não parou mais, alcançando, através da tecnologia do final do século XX e início do XXI, a substituição parcial da mão-de-obra humana por robôs.

O desenvolvimento da indústria e do comércio trouxe consigo a inserção de novas tecnologias ampliando as bases produtivas com vistas ao incremento dos lucros. 0 referido processo teve início no final da Idade Média, em meados do século XVIII, na Inglaterra e expandiu-se pelo Ocidente a partir do Século XIX. Era a consolidação do capitalismo e de sua economia de mercado.

O intuito do capitalismo é o acúmulo de riquezas e de lucro, podendo ser alcançados por diversas, principalmente através do aumento dos preços.

Uma das ferramentas com que se armam os donos dos meios de produção para alavancar a elevação de preços é a formação de cartéis. Eles consistem em ajuste expresso ou tácito entre empresas independentes com vistas a fixar preços ou minorá-los de forma predatória a fim de eliminar a concorrência e posteriormente o oligopólio eleva os preços extorquindo os consumidores.

Os oligopólios cartélizados aumentam os preços, diminuem a concorrência e impedem a inserção no mercado de novas tecnologias, prejudicando assim os consumidores ao tornar bens e serviços mais caros ou indisponíveis.

O cartel é uma das fases autoritária do poder econômico privado, inviabiliza os pressupostos da economia de mercado (liberdade de iniciativa, de concorrência e de contratar), bem como é o uso não social e ilegal das propriedades dos bens de produção e de seus resultados (bens e serviços). 
Em uma dimensão empírica, através de dados coletados em instituições como a Organização para a Cooperação e Desenvolvimento Econômico (OCDE) que pesquisam os cartéis, constata-se a ocorrência de um dano aos consumidores estimável em bilhões de reais, uma vez que a cartelização, quanto aà majoração de preços, opera com um sobrepreço em torno de até $20 \%$ (vinte por cento) em relação ao mercado livre.

No Brasil a legislação que veda os cartéis é a Lei n. 8.884/1994 (sanções administrativas), a Lei n. 8.137/1990 (punição penal), além da responsabilidade civil dos seus patrocinadores pelos ilícitos cometidos na ordem econômica, conforme os art. 186, 187 e 927 do Código Civil.

Destacamos para fins do artigo, a Lei n. 8.884/94 que objetiva prevenir, reprimir e punir os cartéis e todas as formas de abuso do poder econômico, protegendo assim os mercados e os consumidores, limitando paralelamente 0 uso da propriedade dos bens de produção, criou o Sistema Brasileiro de Defesa da Concorrência (SBDC), composto de três órgãos: Secretaria de Acompanhamento Econômico (SEAE), Secretaria de Direito Econômico (SDE) e o Conselho Administrativo de Defesa Econômica (CADE).

A Lei Delegada n. 04/62 também é outro instrumento poderoso estatal, mais precisamente da União, a fim de intervir da propriedade privada dos bens de produção, especificamente nos preços de bens e serviços praticados, através do congelamento ou tabelamento, quando for necessário garantir o consumo do povo em virtude de abusos cometidos pelos oligopólios cartelizados.

\section{Do neoliberalismo de regulamentação ao neoliberalismo de regulação}

\section{Estado Social}

O Estado Direito liberal perdurou desde a derrubada do Ancién Regimen, entretanto se esgotou a partir das mutações da humanidade, do crescimento das cidades e das pressões sociais oriundas das massas populares clamando por melhores condições de vida, de trabalho, de saúde e de educação.

Com o rompimento do liberalismo econômico pelo Estado Social, no denominado Neoliberalismo de regulamentação, o Estado passa a intervir agudamente na economia para salvar os mercados de suas crises cíclicas e amainar as reivindicações das classes trabalhadoras e populares. 
Conforme explica Maulaz (2010) "A ordem liberal é posta em xeque com 0 surgimento de idéias socialistas, comunistas e anarquistas". Acentua ainda com a contribuição de Carvalho Neto que "a um só tempo, animam os movimentos coletivos de massa cada vez mais significativos e neles reforça com a luta pelos direitos coletivos e sociais". ${ }^{3}$.

Acrescenta, ainda, Lucas Verdú que "Nesse momento da história do liberalismo, seu movimento e sistemas sofreram 'diversas transformações à medida que conectaram com outros movimentos ou reformaram seu quadro institucional para se ajustar a novas exigências sociais'"14.

A ordem liberal cede, portanto seu lugar para o Estado Social que promete fixar melhores condições de vida para a sociedade. Neste sentido além da liberdade, se afirmava no Estado Social a busca pela igualdade alicerçando assim a base do triângulo do pensamento iluminista do Século XVIII.

No Estado Social o sistema econômico passou a ser o neoliberalismo de regulamentação, delineado pela significativa presença estatal na economia, especialmente em atividades consideradas essenciais e de custo elevado na época.

Ensina Clark (2008):

Durante a guerra fria, no século passado (1945 a 1990), imperaram na economia de mercado as políticas econômicas neoliberais de regulamentação, em que o Estado Nacional transfigurou-se em Social, realizando a sua atuação no domínio econômico diretamente, via empresa pública, sociedade de economia mista e fundações; ou indiretamente, por meio das normas legais de direito. Tudo em nome do desenvolvimento ou do crescimento.

Naqueles tempos de regulamentação, os capitais privados eram investidos internacionalmente na indústria de consumo, mas também na rendosa indústria armamentista. Assim sendo, o poder econômico privado nacional e internacional precisava da ação estatal em setores de baixa lucratividade, de riscos financeiros ou carentes de investimentos tecnológicos, como as áreas de infra-estrutura (energia, estradas, água

\footnotetext{
${ }^{3}$ CARVALHO NETTO, Menelick de. Requisitos paradigmáticos da interpretação jurídica sob o paradigma do Estado democrático de direito. Revista de Direito Comparado, Belo Horizonte, n. 3, p. 478, mai., 1999.

${ }^{4}$ LUCAS VERDÚ, Pablo. Curso de derecho politico. Madrid: Tecnos, 1992. v.1. p. 226. Apud., BARACHO JÚNIOR, José Alfredo de Oliveira. Responsabilidade civil por dano ao meio ambiente. Belo Horizonte: Del Rey, 2000. p. 55.
} 
potável, telefonia) e social (educação, saúde, previdência), a fim de possibilitar o progresso da economia de mercado, refrear os movimentos sociais reivindicativos (dos trabalhadores, por exemplo) e remover o fantasma do socialismo. Dessa forma, norteavam-se as ações econômicas públicas, reservando à iniciativa privada ampliação de seus ganhos (CLARK, 2008, p. 208).

Assim sendo, no neoliberalismo de regulamentação os detentores do capital se afastam propositadamente de setores da economia nacional onde se fazia necessário altíssimos investimentos financeiros na construção de infra-estruturas como nos setores de energia, telecomunicações, portuários, dentre outros, e serviços essenciais não atrativos ao capital (saúde e educação), mas fundamentais a sobrevivência das massas populares.

Construídas as infra-estruturas naquelas atividades cujo os lucros anteriormente inexistiam ou eram reduzidos, implementados is serviços essenciais, eis novamente a burguesia capitalista retomando as antigas bandeiras e se apossando daquelas atividades e serviços, fincando o domínio econômico privado com aqueles, agora lucrativos. Aí se inicia o neoliberalismo de regulação.

O Neoliberalismo vem sendo adotado pelas Constituições brasileiras. Coincidindo com o seu caráter anfíbio, a Ordem Jurídica consagrada nas Cartas é submetida a técnica de expressão enumeradora de "princípios", ou até mesmo portadora de definições, com freqüência representando oscilações de caráter ideológico asseguradas pelo expediente das "revisões" e das "emendas" ao texto original.

Correspondendo a essas modalidades, manifestam-se os respectivos regimes. Quando dirigido no sentido de mais ampla presença do poder econômico do Estado no domínio econômico, ou seja, do Estado Máximo, temos o Estado "dirigente", "planejador", "regulamentador", impropriamente chamado "intervencionista", como se verá adiante. Quando a sua presença se torna menor, configura-se o Estado Mínimo, livre-concorrencial e, quando muito, "regulador" (SOUZA, 2005, p. 315).

No Estado Social, por múltiplos motivos, alguns citados acima, parcela das propriedades de produção eram estatais. Contudo persistia o mercado, o poderio dos agentes privados naquele, o planejamento publico da economia a fim de executar o crescimento modenizante ou o desenvolvimento, assim como a existência de comandos 
legais restritivos e positivos para as propriedade privadas de produção (grande maioria em sociedade).

\section{Estado Democrático de Direito e a regulação}

Na visão dos reguladores, bem diferente da nossa, a inclusão social não é apenas um ideal, mas uma necessidade social realizada pelo mercado auto-regulador. Portanto, no mundo global não caberia mais ao Estado agir na economia, ou melhor, deveria atuar apenas regulando.

Assim sendo, os poderes públicos deveriam afastar-se de determinados setores da economia transferindo-os para iniciativa privada, atividades e serviços que antes realizava, de modo a abastecer os cofres públicos através da alienação patrimonial e de arrecadação de impostos, liberando assim recursos financeiros e humanos públicos para áreas de relevância.

A dita nova técnica estatal de atuação na vida econômica, a regulação, é uma tentativa de buscar o paraíso perdido do funcionamento da economia, pela suposta "lei natural" de oferta e procura. Contudo com a regulação e fiscalização dos poderes públicos se faria face as constantes falhas de mercado, digo, ao arbítrio do poder econômico privado cartelizado (exemplificando). Uma das bases teóricas da regulação, segundo Clark (2009), é a Escola de Chicago, que pregava o fim das empresas estatais dentre outras ações.

O Neoliberalismo de regulação se apresenta como substituto do modelo francês de Neoliberalismo de regulamentação, passando o Estado a ser mero regulador da economia de mercado. Neste cenário, o Estado surge em defesa dos consumidores e cidadãos interferindo no direito de propriedade do particular (de produção) combatendo o abuso do poder econômico em todas as suas espécies.

A regulação estatal da economia é o conjunto de medidas legislativas, administrativas e convencionais pelas quais o Estado, restringindo a liberdade privada (sobretudo da propriedade privada dos bens de produção) ou pela via indutiva, determina, controla ou influencia o comportamento dos agentes econômicos, evitando que eles lesem os interesses sociais definidos no marco da Constituição e orientando-os em direções socialmente desejáveis. 
Transformado o Estado Social em Estado Democrático de Direito, fecha-se os lados do triângulo iluminista e é na concepção de fraternidade que o homem pós-moderno alimenta as pressões sociais sobre o Estado privatizador de serviços e de atividades produtivas.

Nesta perspectiva regulatória são criadas as agências de regulação para quase todos os setores em que o Estado empresário se afastou, mas devido aos aspectos socioeconômicos é essencial a presença do normatizador Estado Democrático de Direito, tendo como principal objetivo dar "efetividade à fluidez natural" do mercado.

Ressalta M arques (2005):

Já às entidades reguladoras sectoriais, cumpre acautelar e promover, numa perspectiva ex ante, o melhor funcionamento dos mercados sob sua regulação. E a regulação surge tipicamente em mercados onde a concorrência não produz os efeitos benéficos desejados, normalmente devido a falhas de mercado.

Do ponto de vista económico, a regulação justifica-se naqueles sectores em que, por razões económicas (p. ex., tecnologia ou procura) não há condições para a concorrência se materializar ou desenvolver como nos mercados típicos.".

As agências de regulação atuam em inúmeros setores no Brasil, tais como: saúde e previdência privada, cinema, água e esgoto vigilância sanitária etc. Aquelas são pessoas jurídicas de direito público interno, constituídas sob forma de autarquias, ou seja, como entes públicos da administração indireta do Estado cuja finalidade é regular e fiscalizar o mercado.

Com a regulação, usada como único remédio salvador do mundo e protegida de grandes contestações pela mídia dos "donos do poder" (FAORO, 2000), o Estado passou a adotar uma nova técnica de ação na vida econômica, ou seja, o neoliberalismo de regulação. 0 poder estatal continuou a intervir indiretamente no domínio econômico, através das normas legais (leis, decretos, portaria); assim como de forma intermediária, via agências de regulação. Todavia, diferentemente das empresas estatais, as agências não produzem bens ou insumos nem prestam serviços à população, mas somente fiscalizam e regulam o mercado ditando "comandos técnicos" de expansão, qualidade, índices de reajuste de preços/tarifas, etc.

Porém, é prudente frisar, que a técnica intervencionista de regulação permite a existência de algumas empresas estatais, em menor número, atuando no âmbito do mercado. Contudo, sem desempenhar o papel anterior e possuindo uma reduzida capacidade de ingerência na vida econômica e social (CLARK, 2008, p. 209) 
A regulação estatal, enquanto técnica de atuação dos poderes públicos na esfera econômica e social, estabelece limites ao uso da propriedade dos bens de produção, bens como ações positivas, por intermédio de diversos instrumentos legais fixando preços mínimos, valores de correção monetária para os preços praticados, inserção obrigatória de tecnologia, expansão das atividades, forma de atendimento ao consumidor, etc. Ela visa contribuir na efetivação dos comandos de nossa constituição, apesar de na pratica não conseguir.

No Estado Democrático de Direito, a regulação reduz as suas propriedades dos meios de produção, diminui-se o a sua roupagem enquanto empresário, apesar de não elimina-lo, dilatando, por outro lado, amplia-se a apropriação privada daqueles bens voltados a produção. Todavia as desigualdades sociais aprofundaram, persiste a concentração de riquezas, bem como o desrespeito da Constituição brasileira permanece. Isso sem falar da crise financeira internacional gerada pelo neoliberalismo de regulação.

\section{Considerações Finais}

O homem em sua dimensão de ser humano tem apreendido que 0 acúmulo de riquezas the garante uma dimensão de poder que altera todas as suas relações. Engels (2007) ao escrever sobre as origens da família e da propriedade privada, através das contribuições do antropologista norte-americano Lewis Henry Morgan (1818-1881), nos revela que a partir do enriquecimento de pastores, através da domesticação de animais, esta figura doce e singela do pastor passou a ser mais importante que do lendário guerreiro e caçador, simplesmente porque era rico e ainda proprietário.

A partir de então, as famílias que viviam em grupos denominados comunistas, compartilhando trabalho, alimentação e propriedade comum, deixaram de ser matriarcais para serem patriarcais, a propriedade passou a ser transmitida consanguineamente. Era 0 nascimento do domínio privado da propriedade dos bens de produção.

Ao passarem a ter bens próprios, os homens passaram a ter sobras que eram usadas em escambos inicialmente esporádicos, posteriormente regulares, evoluindo deste estágio para a participação nos escambos dos atravessadores, também chamados de comerciantes, e da invenção da moeda. 
0 enriquecimento dos comerciantes Ihes garantiu construir e derrubar o modelo feudal do sistema econômico mercantilista, uma vez que a intervenção estatal na economia dos Estados-Nacionais Ihes restringia o comércio, até que as demandas sociais das grandes massas e as crises cíclicas do sistema suplantaram os modelos liberais de Estado de Direito dando lugar aos governos de políticas socioeconômicas neoliberais de regulamentação, primeiro, e depois de regulação.

No Brasil, alguns setores da economia, tais como o serviço bancário, as redes de farmácias e supermercados são oligopolizados cartelizados realizadores de abuso do poder econômico, em regra, no exercício da propriedade privada dos bens de produção, resultando assim em prejuízos aos consumidores, cativos no mercado tupiniquim.

A formação de cartéis, portanto, viabiliza a intervenção do Estado no domínio econômico do setor privado, de acordo com os arts. 173, parágrafo 4 e 174 da Constituição brasileira de 1988 que permitem a punição e repressão do abuso do poder econômico privado, bem como o controle de preços através do congelamento e do tabelamento.

Ao intervir na economia o Estado materializa princípios fundamentais dentre os quais o primado da justiça, evitando que o poderio econômico de grupos corporativos identificados com o espírito do capitalismo, da busca frenética por lucros, lesem os consumidores e a sociedade de maneira geral, através de práticas abusivas utilizando-se dos meios de produção.

A Constituição brasileira de 1988 institui comandos imperativos determinado à conquista de uma sociedade transformada a partir das bases produtivas geradoras de bens estar social e felicidade. Para tanto, fixou o enquadramento dos bens ou meios de produção privado, seja pelo víeis restritivo e positivo, sendo eles um dos grandes responsáveis pelas mutações de nossa realidade social caótica. Assim sendo, não nos cabe cumprir outra missão, a não ser efetivar o designo constitucional transformador, enquadrando legalmente aqueles tipos de bens, com base nos art. 170, III; 173, parágrafo 4, 174, dentre outros tantos artigos.

\section{Referências}

ARAGÃO, Alexandre Santos de. Agências Reguladoras e a Evolução do Direito Administrativo Econômico. Editora Forense: Rio de Janeiro, 2006. 
Banco Central do Brasil. A origem do dinheiro. Acesso em 3/10/2010. Disponível em: http://www.bcb.gov.br/?ORIGEM OEDA

BARRETO, Lucas Hayne Dantas. Função social da propriedade. Elaborado em 08/2005. Acesso em 7/9/2010. Disponível em: http://www1.jus.com.br/doutrina/texto.asp?id=7164 BONAVIDES, Paulo. Do Estado liberal ao Estado social. São Paulo: Malheiros, 1996. p. 42.

CLARK, Giovani. 0 mito da regulação e a sua pandemia. Acesso em: 7/12/2009. Disponível em: http:// www.domtotal.com/direito//pagina/ detalhe/23728/0-mito-da-regulacao-e-asua-pandemia

. Política Econômica e Estado. Revista de Estudos Avançados. São

Paulo, v. 22, n. 62, p. 207-217, jan/abr. 2008.

ENGELS, Friedrich. A origem da família, da propriedade privada e do Estado. São Paulo Tradução: Ciro Mioranza. Ed. Escala. 2a . Ed. Revisada, 2007.

Novo dicionário de Direito Econômico. Fundação Brasileira de Direito Econômico. Coord. NASCIM ENTO, Floriano de Lima. CLARK, Giovani. Org. CAM ARGO, Ricardo Antônio Lucas. Porto Alegre: Sérgio Antônio Fabris, 2010.

GRAU, Eros Roberto. A ordem econômica na Constituição de 1988 (Interpretação e Crítica). 14a. Ed., Malheiros Editores Ltda, São Paulo: 2010.

LÉPORE, Paulo Eduardo. A função social da propriedade. Acesso em 7/9/2010. Disponível em: http://docs.google.com/viewer?a $=v \& q=$ cache:L6o-

jhRlqpUJ:www.revistajuridicaunicoc.com.br/midia/arquivos/ArquivolD_14.pdf+fun\%C3\%A7 $\%$ C3\%A3o +social +da+propriedade\& $\mathrm{hl}=\mathrm{pt}-$

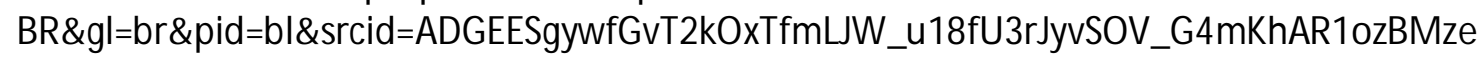
q23YHa_iuEzYnM rM P21s8pEQIxqLol6SX-

cB8GzE3̄KDt7a7YqERyG75IrfJnRBchqBeG0TqII7Ax0GnE2ehtwEGf\&sig=AHIEtbSf2bVamGi2pn cmlegvJJYVYM E5tg

M ARQUES, M aria M anuel Leitão et. al., Concorrência e Regulação - A Relação entre a Autoridade da Concorrência e as Autoridades de Regulação Sectorial, Vol. 6, Direito Público e Regulação, Coimbra: Coimbra Editora, 2005.

M AULAZ, Ralph Batista de. Os paradigmas do Estado de Direito - O Estado Liberal, o Estado Social (Socialista) e o Estado Democrático de Direito. Acesso em: 1/10/2010. Disponível em: www.atame-df.com.br/material/doc/mat06032401.doc

M EIRELLES, Hely Lopes. Direito Administrativo Brasileiro. 29a Ed. São Paulo: Malheiros Editores, 2004. 
PEREIRA, William Eufrásio Nunes. Do Estado liberado ao neoliberal. Acesso em: 1/10/2010. Disponível em:

www.ccsa.ufrn.br/.../1\%20Do\%20Estado\%20Liberal\%20para\%200\%20Neoliberal.pdf.

SOUZA, Washington Peluso Albino de. Primeiras linhas de Direito Econômico. 6 ed. São Paulo: LTr. 2005.

Sã̃o Paulo: LTr, 2008.

. CLARK, Giovani. Questões Polêmicas de Direito Econômico.

Artigo recebido em:

26 jul. 2011

Artigo aprovado em:

14 nov. 2011 